\title{
LINEAR ESTIMATION OF GIRTH AS A COVARIATE ON YIELD PARAMETERS OF RUBBER (Hevea brasiliensis Muell.Arg.): CORRELATION OF GIRTH WITH LATEX VOLUME AND WEIGHT.
}

\author{
P.M.A.S.Karunaratne ${ }^{1}$, A.W.Wijeratne ${ }^{1}$ and J.B.D.A.P..Kumara ${ }^{1}$
}

\begin{abstract}
Rubber, (Hevea brasiliensis Mull.Arg). plays an important role in the Sri Lankan economy as one of the main export agricultural crops in the country. Latex is the economically important part of rubber tree for which the girth increment is a very important factor to ensure higher latex yield. It is known fact that girth related to the latex yield of rubber. Therefore the current study was conducted to estimate the girth as covariate for rubber yield and to predict the correct out come of future experiments related to rubber.

The relationships of latex yield and girth of rubber were estimated using a linear regression model. Three clones RRIC 100, RRIC 121 and PB 86 were used for the experiment. Latex yield was determined by latex volume of individual trees and Grams per Tree per Tapping (GTT). Each clone was categorized into 3 girth classes as poor girth (class 1,50-64 cm), medium girth (class 2, 65-79 cm) and high girth (class 3, $>80 \mathrm{~cm}$ ). The regression coefficient for RRIC 100 was +1.520 and +0.466 for GTT and latex volume respectively. The recorded regression coefficients for clone RRIC 121 were +0.690 for GTT and +1.192 for latex volume. Similarly PB 86 produced regression coefficients +0.602 for GTT and +1.582 for latex volume. The significance by positive correlation between latex yield and girth in tested clones suggested that tree girth can be taken as a covariate in rubber experiments.
\end{abstract}

\section{INTRODUCTION}

Sri Lanka has an agriculturally based economy of which the plantation sector consists of tea, rubber and coconut. Although industrial exports bring in a higher percentage of foreign exchange earnings agriculture is the biggest net earner to the country. Rubber, (Hevea brasiliensis Muell.Arg). plays an important role in the Sri Lankan economy as a foreign exchange earner, commodity for domestic consumption and a source of employment.

The economically important part of rubber is latex. To have a higher number of latex vessels, girth increment is a very important factor. To attain economic yield, the general health, girthing of the tree must be maintained at a satisfactory level. Moreover, the number of latex vessels, their size and starch reserves in the bark are related to the tree girth and latex yield (Nugawela, 1998).

Being a perennial crop, experiments related to rubber to enhance the latex production is normally done in already established fields. Latex yield is primarily dependent on the tree girth. In an average rubber estate, girths of rubber trees are different from tree to tree. If an experiment would be planned to carry out using such heterogeneous trees, there is an obvious chance to mask the actual results of that particular experiment. So there is an urgent need for estimation of a covariate for rubber yield to ensure the correct outcomes of future experiments.

The rubber trees of the same stand can be of different ages (due to replanting and filling) and also of different girth sizes. Blocking of the land will be led to trees of different sizes to be present within the same plantation. In such cases the response measured has to be adjusted in some way to improve precision in the overall experiment. The analysis of covariance is much useful in adjusting the response measurements (i.e. Rubber latex yield) which is influenced by covariate (i.e.. Girth of rubber tree).

In this technique the covariate (the girth of the tree) should be correlated to the response variable and should not be 
affected by the treatments. Since the girth measurement is made prior to the experiment, one can be sure that the treatment does not affect the covariate. The current study will provide the information about coefficients for the correlations of tree girth and yield parameters of clonal rubber. Therefore, these data could be used in other experiments considering girth as covariate.

It has been already established that girth of the rubber tree is positively correlated to the latex yield of rubber (Thatill, 1998). Covariance analysis has been used for genetic experiments widely. According to Li Xinhai, et.al, (1999) genetic correlations for seed yield and protein percentage in soybean (Glicine max) were large and negative for branch number with both seed yield and protein content. Seed protein content was both positively and negatively associated with maturity (Kwon \& Torrie, 1964). In a related study (Xiong et. al, 1988) revealed the use of covariates in correlation analysis of several quantitative characters of barley.

This technique of adjusting the treatment means using a supplementary variable (covariate) is called covariance analysis. This increases the precision of the experiment. Therefore use of a covariate in experiments of rubber is of utmost importance.

The primary objective of this study was to determine the correlation coefficient of tree girth and yield parameters of rubber to consider girth as a covariate in future experiments.

\section{MATERIALS AND METHODS}

The study was carried out in fields of new clearings at Bogawantalawa Plantations Ltd, Udabage Group, Daraniyagala, Sri Lanka (6.4' N, 80.25' E and 60m.a.m.s.1.). The annual rainfall is $2500 \mathrm{~mm}$ and the daily mean maximum and minimum temperatures are $27^{\circ} \mathrm{C}$ and $32^{\circ} \mathrm{C}$ respectively.

\section{Plant materials:}

Plants were selected from existing plants in the field, which were planted in 1988. Three major clones in Udabage Group, Bogawantalawa Plantations namely RRIC 100, RRIC 121 and PB 86 were used for the determination of girth and latex yield. Tree girth was measured at $120 \mathrm{~cm}$ above the bud union in individual trees. Three girth classes were designed according to the girth of the plants as poor girth (class 1,50-64 cm), medium girth (class 2, 65-79 $\mathrm{cm}$ ) and high girth (class $3,>80 \mathrm{~cm}$ ).

\section{Latex yield:}

To measure the latex yield fifteen plants were randomly chosen from each clone, each girth at each sample date. Crop dry rubber content was measured using metrolac. Dry rubber content was directly taken from the calibrated chart. These measurements were continued for three months period.

Latex volume produced by each trees was recorded during the collection of latex. Volume recorded by individual tree and metrolac reading of the class was used to estimate Grams per Tree per Tapping (GTT).

Volume of latex * DRCY = GTT .

\section{Data analysis}

All data were analyzed using MINITAB, a commonly used statistical software package. Ordinary Least Square (OLSq) technique was used to estimate the parameters of linear regression models. In selected models, Coefficient of Determination $\left(\mathrm{R}^{2}\right)$ and Correlation coefficient were also obtained. Further, normal probability plots of the residuals of estimated models were also obtained to support the results to satisfy the assumptions made on error term of linear regression model. 


\section{RESULTS AND DISCUSSION}

The regression coefficients in this experiment were examined for three different clones and their corresponding latex yield as volume per individual trees and Grams per Tree per Tapping (GTT) were measured (data not presented). The latex volume and GTT showed a linear relationship with the tree girth.

Table 01. The regression coefficients and $R^{2}$ of estimate models in rubber clones (RRIC 100, RRIC 121 and PB 86) for latex volume of individual trees and Grams per Tree per Tapping (GTT)

Regression coefficient

\begin{tabular}{rcr}
\hline Clone & \multicolumn{2}{c}{ Regression coefficient } \\
& $\begin{array}{l}\text { Latex volume } \\
\text { GTT }\end{array}$ & \\
\hline RRIC 100 & +1.5204 & +0.4666 \\
RRIC 121 & +1.1920 & +0.6906 \\
PB 86 & +1.582 & +0.603 \\
\hline
\end{tabular}

The regression coefficients for GTT and latex volume of individual trees were estimated for each clone. Within girth classes 1,2 and 3 there is a significant effect of girth on yield. The significant level is 0.001 . Clone RRIC 100 had the slopes of for GTT $(+0.466)$ and $(+1.5204)$ for volume of latex in leaner regression model(Figure 01). Similarly RRIC 121 recorded the positive correlation of girth and yield parameters. According to the regression analysis, the regression coefficients of all models were significant in all three girth classes at the level of 0.001 probabilities. The regression coefficients were +0.690 and +1.192 for GTT and volume of latex in individual trees, respectively.

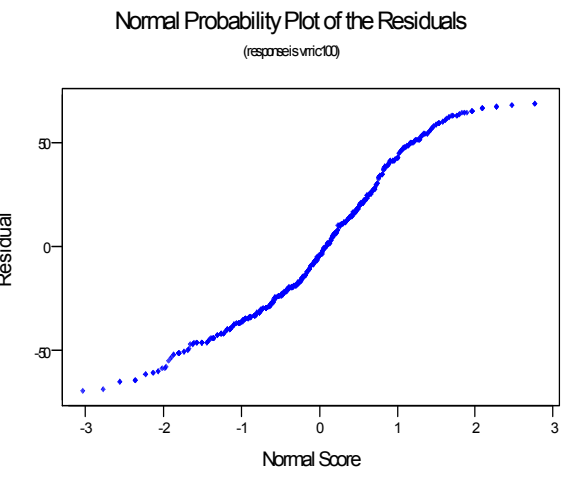

(A)

(B)

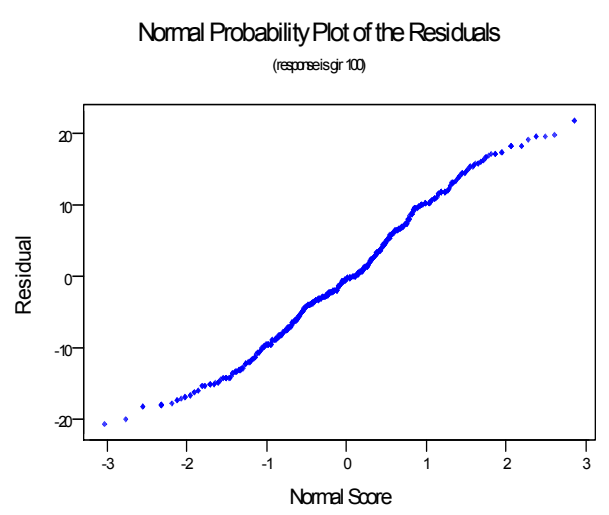

Figure 01. Variation of residual error with normal probability distribution of GTT (A) and individual latex volume (B) in RRIC 100. The regression equations are $Y=-12.4+0.467$ and $Y=$ $27.8+1.52$ respectively. 
(A)

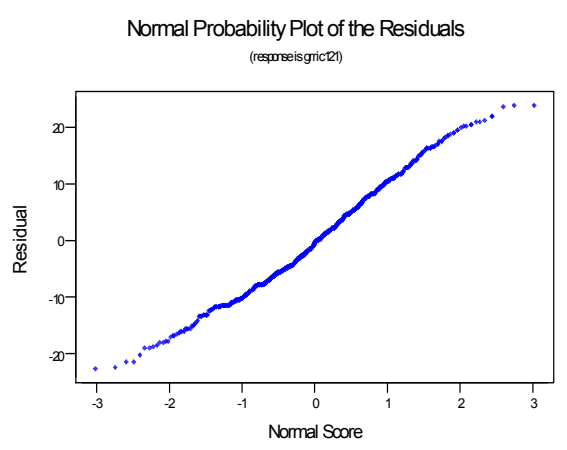

(B)

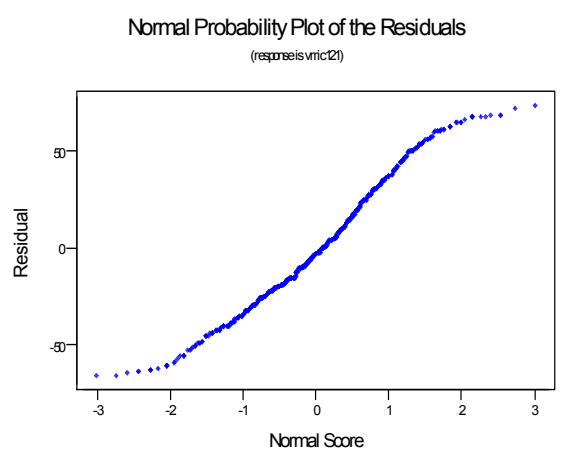

Figure 02. Variation of residual error with normal probability distribution of GTT (A) and individual latex volume (B) in RRIC 121. The correspondence regression equations are $\mathrm{Y}=\mathbf{- 3 1 . 7}$ +0.691 and $Y=-31.7+1.19$ respectively.

Further, the regression coefficients of PB86 was significant at 0.001 probability (between girth and the latex yield in three different girth classes). Regression coefficient GTT of +0.602 and +1.582 was recorded for GTT and latex volume of individual trees respectively to the clone PB 86. Figures 02,03, and 04 shows normal probability of the residuals of the estimate model for rubber clones RRIC 100, RRIC 121 and PB 86 respectively. In all normal probability plots the relationships with residuals and normal score are almost linear. This indicates the error term of estimated models satisfy the assumption
(A)

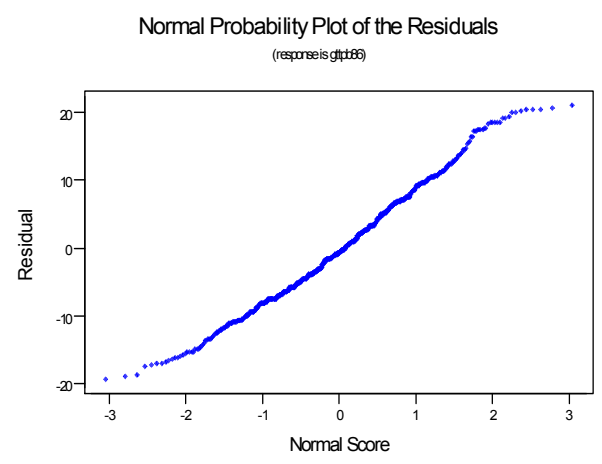

(B)

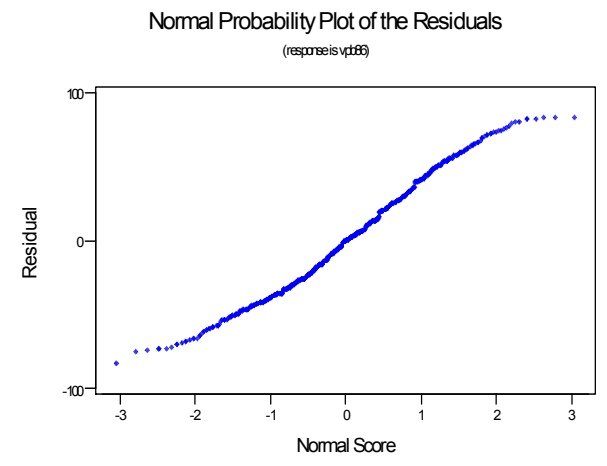

Figure 03. Variation of residual error with normal probability distribution of GTT (A) and individual latex volume (B) in $P B$ 86. The correspondence regression equations are $\mathrm{Y}=\mathbf{- 2 5 . 0}$ +0.603 and $Y=-34.9+1.58$ respectively.

made on it for better model selection in OLSq estimates.

Girth has been used extensively as parameters in growth and yield estimation of tree crops. It is the relationship to yield, providing a means of assessing the growth factor in clonal performances. Girth and number of latex vessels with in the cortical tissue have together account for yield (Nugawela, 1998). According to the experimental evidences, the yield of rubber is determined by four major components such as initial flow rate, 
length of tapping cut, dry rubber content and plugging index. Further, constants of the linear expression had positively correlated with the total number of latex vessel rings, bark thickness and distance between consecutive latex vessel rings but not the density or diameters of latex vessels or sieve tubes.

The positive relationship of girth with two different yield parameters was of particular interest in this study (Table 01). Higher girth classes among the tested clones RRIC 100, RRIC 121 and PB86 had higher latex yield in terms of volume per individual tree and GTT (data not presented). These results indicated that the close association of girth with latex yields in tested clones.
Girth of the Hevea is one of the most important structural factors, which determined the rubber yield with in clone (Xie Hul et.al, 1998). According to the experimental data of Xie Hul et.al, (1998), corresponding increase in bark thickness should obviously increase the bark area available for latex production and drainage of latex.

\section{CONCLUSIONS}

There is a positive relationship of girths with latex volume and GTT of all the clones used in this experiment (Figures 01,02,03). This shows that one unit of girth increment results the increase in GTT and volume of latex. Further girth can be used as a covariate in future experiments of rubber in tested clones. The regression coefficients in three clones can be used as a factor for the adjustment of the treatment effect.

\section{REFERENCES}

Proceedings of International Rubber Conference (1984) Rubber Research Institute Sri Lanka, Kwon S.H. and J.H. Torrie (1964). Heretability and interrelationship among traits of two soybean populations. Crop Science, 4, pp. 196-198.

Liyanage,A.De.S and O.S.Peries, (1994). Practical guide to Rubber Plantation and Processing RRISL, 68, pp. 11-16.

Li Xinhai, W. Jinling, Y. Qingkai, J. Shaojie and W. Liming (1999). The effect of selection method on the association of yield and seed protein with agronomic characters in an interspecefic cross of soybean in Soybean Genetics Newsletter.

Nugawela A. (1998). Yield decline in plantation can excessive double tapping be a course ? Bulletin of Rubber Research Institute of Sri Lanka, 38, pp. 43-49.

Thatill R.O. (1998). Covariance analysis in Design and Analysis of Experiments in Design and Analysis of Experiments , pp. 40-43. 